\title{
Le plan Stoica et les relations entre la Roumanie et la Grèce au tournant de la guerre froide (1957)
}

The Stoica Plan and the Relationship between Romania and Greece at a Turning Point in the Cold War (1957)

Planul Stoica și relaȚiile dintre România și Grecia într-un moment de cotitură în războiul rece (1957)

Irina Gridan

\section{OpenEdition}

Journals

Édition électronique

URL : https://journals.openedition.org/ceb/9664

DOI : $10.4000 /$ ceb.9664

ISSN : 2261-4184

Éditeur

INALCO

Édition imprimée

ISBN : 978-2-85831-239-9

ISSN : 0290-7402

\section{Référence électronique}

Irina Gridan, «Le plan Stoica et les relations entre la Roumanie et la Grèce au tournant de la guerre froide (1957) », Cahiers balkaniques [En ligne], 44 | 2016, mis en ligne le 04 décembre 2017, consulté le 07 juillet 2021. URL : http://journals.openedition.org/ceb/9664; DOI : https://doi.org/10.4000/ceb. 9664

Ce document a été généré automatiquement le 7 juillet 2021.

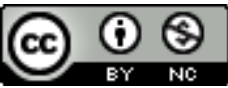

Cahiers balkaniques est mis à disposition selon les termes de la Licence Creative Commons Attribution - Pas d'Utilisation Commerciale 4.0 International. 


\section{Le plan Stoica et les relations entre la Roumanie et la Grèce au tournant de la guerre froide (1957)}

The Stoica Plan and the Relationship between Romania and Greece at a Turning Point in the Cold War (1957)

Planul Stoica și relaȚiile dintre România și Grecia într-un moment de cotitură în războiul rece (1957)

\section{Irina Gridan}

1 Du point de vue des relations Est-Ouest, le milieu des années 1950 constitue un tournant dans la guerre froide : l'adoption par l'URSS de la doctrine de la coexistence pacifique, après le XX $\mathrm{XX}^{\mathrm{e}}$ Congrès du Parti communiste de l'Union soviétique (PCUS), en 1956, en constitue l'illustration la plus emblématique. Pour autant, ce virage idéologique promu par Nikita Khrouchtchev trouve-t-il des réalisations concrètes dans les politiques extérieures des États satellites de l'Union soviétique? Les alliés des États-Unis bénéficient-ils à leur tour d'une plus grande latitude dans le choix et l'approfondissement de leurs partenariats extérieurs ? Si la guerre froide a souvent été synonyme pour les deux Grands d'affrontements par alliés interposés, la relative détente internationale qui marque le milieu des années 1950 se traduit-elle concrètement par des rapprochements - désormais possibles, en théorie -, entre ces mêmes alliés? En raison de leur proximité géographique et culturelle, et de la profondeur historique de leurs relations, le cas des relations bilatérales entre la Roumanie et la Grèce offre un excellent observatoire. Il apporte en effet des éléments de réponse à cette question en permettant de jauger la marge de manœuvre des diplomaties roumaine et grecque, chacune étant dans l'ombre respective de l'URSS et des États-Unis. L'objectif est bien ici d'interroger les spécificités et les similarités des rôles de la Roumanie et de la Grèce dans des dispositifs géopolitiques qui les transcendent, en s'interrogeant à travers cette étude sur le caractère mouvant des frontières de guerre froide: en un mot, les blocs peuvent-ils avoir une géographie variable? Nous aborderons les enjeux du rapprochement roumano-grec à travers 
l'analyse du plan Stoica, un plan de coopération balkanique. Il s'agira dans un premier temps de voir en quoi consiste ce projet, dont la Roumanie est l'émettrice, et la Grèce, l'un des principaux destinataires. Nous nous intéresserons ensuite aux objectifs du rapprochement roumano-grec et à ses limites, avant d'en voir les retombées en matière de propagande. Ce faisant, nous montrerons que du côté roumain - et soviétique - le plan Stoica entend œuvrer à la déstabilisation périphérique du bloc de l'Ouest ; du côté grec, ce plan permet d'exercer une sorte de chantage autour de la participation à l'Alliance atlantique ${ }^{1}$.

\section{Le plan Stoica, un projet de coopération balkanique}

2 Mais d'abord, qu'est-ce que le plan Stoica? Rappelons qu'en 1957, les conseillers et les spécialistes soviétiques quittent le territoire roumain à grand renfort de propagande ${ }^{2}$. Le démantèlement de cette institution mise en place dès le milieu des années $1940^{3}$, qui constituait un puissant relais de l'influence soviétique et un véritable "État dans l'État ${ }^{4}$ ", semble marquer pour la Roumanie le début d'un processus d'affirmation sur la scène diplomatique européenne, puis internationale. C'est en effet dans ce contexte que la République populaire roumaine (RPR) lance une initiative au plan régional, qui se veut une illustration concrète du nouvel esprit que l'Union soviétique appelle de ses vœux dans ses relations avec les « démocraties populaires». Ce dernier a été explicité dans la déclaration du gouvernement soviétique du 30 octobre 1956 qui, en pleine crise hongroise, évoquait notamment " la nécessité de tenir pleinement compte de l'histoire passée et des particularités de chaque pays", mais, aussi, et surtout, la nécessité d'«éliminer toute possibilité, quelle qu'elle soit, de violation du principe de souveraineté nationale ${ }^{5}$. D'après la lettre de cette déclaration, il s'agit non seulement de mettre un terme à toute pratique constituant une entorse au principe de l'égalité en droits, ainsi qu'à toute immixtion dans les affaires intérieures, mais également de promouvoir des actions internationales entreprises par ces pays en leur nom propre ${ }^{6}$.

3 Le président du Conseil de la RPR, Chivu Stoica, propose ainsi, en septembre 1957, à ses homologues bulgare, albanais, yougoslave, grec et turc, de se réunir lors d'une conférence. L'objectif affiché est de renforcer la coopération économique et culturelle et de créer une "zone de paix» dans les Balkans. L'invitation adressée le 10 septembre 1957 par Chivu Stoica au Premier ministre grec, Constantin Caramanlis ${ }^{7}$, est teintée d'un esprit très «briandiste": l'objectif est d'instaurer des relations pacifiées entre les pays et les peuples concernés, de créer un "climat de confiance » afin de garantir ensemble leurs frontières communes. L'« entente collective des États balkaniques » que vise la Roumanie doit constituer un dispositif de sécurité régional, précurseur d'un « système européen général de sécurité »: tous les États, "grands et petits ", doivent ainsi contribuer à "la détente dans les relations internationales $»^{8}$. Nous sommes bien dans l'ère de la coexistence pacifique. Les autorités de Bucarest ne s'en cachent pas, il s'agit de renouer avec un processus amorcé dans l'entre-deux-guerres par une diplomatie roumaine alors dirigée par Nicolae Titulescu', avec la signature en février 1934 de l'Entente balkanique entre la Roumanie, la Grèce, la Yougoslavie et la Turquie; l'enjeu était alors la garantie commune défensive des frontières, mais l'Entente n'a pas résisté à la guerre. L'entreprise de 1957 porte-t-elle davantage ses fruits? Quel est l'écho de la proposition roumaine? 
Sans surprise, un très bon accueil lui est réservé dans les pays communistes. La Yougoslavie répond favorablement à l'invitation roumaine le 13 septembre, la Bulgarie fait connaitre son acceptation enthousiaste le 19 septembre $^{10}$, l'Albanie, deux jours plus tard. Le dialogue balkanique à six est, en revanche, rapidement compromis par le rejet du projet par la Grèce et la Turquie ${ }^{11}$, qui demeurent irréconciliables sur la question chypriote. Caramanlis décline donc l'invitation, le 23 septembre $^{12}$. Dans son refus, il souligne qu'officiellement son pays est toujours en guerre avec l'Albanie, et qu'il n'a pas normalisé ses relations avec la Bulgarie. Les dossiers contentieux avec la Roumanie, au premier titre desquels l'indemnisation de biens grecs nationalisés en 1948, sont également mis en avant ${ }^{13}$. La proposition roumaine échoue par conséquent à réunir une conférence dans le but de créer une zone de paix et de coopération dans les Balkans.

Ce que l'on nomme dès lors le "plan Stoica " ne cesse pourtant d'étonner: d'abord, parce qu'en incluant la Grèce et la Turquie au nombre des destinataires, il bouscule la logique de bloc, transcendant les frontières du camp communiste au profit d'une logique balkanique ; ensuite, parce que, dans le texte roumain, nulle mention n'est faite de l'Union soviétique, ce qui est non seulement inhabituel, mais inédit. Or il est difficile d'accorder du crédit à l'hypothèse selon laquelle la Roumanie serait passée de la soumission totale à l'égard de l'URSS, manifeste au cours de la crise hongroise de 1956, à une capacité d'initier seule des projets de cette envergure moins d'un an plus tard. Rappelons qu'à la fin du mois d'octobre et au début du mois de novembre, le soutien affiché aux interventions soviétiques à Budapest, ainsi que la condamnation de la "contre-révolution » hongroise ont fait l'unanimité parmi des dirigeants roumains hantés par une possible contagion des revendications frondeuses dans leur pays ${ }^{14}$. Après la seconde intervention soviétique à Budapest, ils ne cessent de rappeler que

le nouveau gouvernement de la République populaire hongroise a appelé à l'aide les troupes soviétiques, qui se trouvent en Hongrie sur la base du traité de Varsovie. Les soldats soviétiques aident les travailleurs hongrois à mettre fin au désordre et au chaos ${ }^{15}$.

6 À la demande des Soviétiques, les Roumains acceptent même que Imre Nagy soit détenu sur leur territoire ${ }^{16}$. Puisqu'il intervient moins d'un an plus tard, il est par conséquent légitime de se demander si le plan Stoica est une initiative véritablement roumaine.

\section{Un projet authentiquement roumain?}

7 Tant le lancement que le contenu du plan Stoica ont en effet de quoi surprendre. D'abord parce que, en 1956, la collaboration balkanique n'était considérée comme une priorité, ni par Chivu Stoica, ni par le président du Conseil bulgare, Anton Yougov : en août, dans une interview accordée à un journal indien, le premier balaye d'un revers de main toute " éventuelle fédération des États socialistes du Sud européen ${ }^{17}$ »; ces propos sont corroborés par le second, qui « rejette, comme absolument ridicules et nocifs, les bruits au sujet d'un prétendu projet de Fédération balkanique ${ }^{18}$ ». Pour ce qui est des termes de la missive roumaine, si la Charte des Nations Unies y figure en bonne place, aucune référence explicite n'est en revanche faite à l'Union soviétique. Les dirigeants soviétiques se gardent d'ailleurs soigneusement de réagir, prenant, semble-t-il, leurs distances et évitant toute déclaration à ce sujet ${ }^{19}$. Seul Troud publie, trois semaines plus tard, un article intitulé « Une précieuse initiative ${ }^{20}$ ». Hormis cette exception, le silence de la presse est total, visant à montrer, de manière ostensible, que l'URSS respecte son 
engagement en faveur de la non-ingérence dans les affaires d'autres États et que, le plan Stoica, c'est l'affaire des Roumains.

Or, contrairement aux déclarations contemporaines du projet, tout comme aux déclarations rétrospectives de certains diplomates - à l'image de Valentin Lipatti ${ }^{21}$-, le plan Stoica est bel et bien un ballon d'essai soviétique, téléguidé depuis Moscou. L'on est en effet dès l'abord frappé par le fait que le projet reprend, à l'identique, les engagements de la déclaration soviétique du 30 octobre 1956 sur les relations entre pays socialistes, dans un langage pétri des poncifs que sont désormais l'égalité en droits et le respect de la souveraineté nationale. Par ailleurs, l'archéologie de la décision contribue à démontrer comment, lors d'entrevues préalables, le projet et les modalités de son lancement ont été mis au point de concert par les protagonistes. Grâce aux documents d'archives, l'on peut en effet resituer très précisément des prises de contact préliminaires entre dirigeants communistes, ayant eu lieu sous l'égide des Soviétiques. Une première rencontre en ce sens a ainsi lieu le 18 juillet 1957, dans les environs de Moscou, entre Nikita Khrouchtchev, Enver Hodja, Todor Jivkov, Edvard Kardelj et Alexandre Rankovitch. Les $1^{\text {er }}$ et 2 août, Khrouchtchev et le maréchal Tito se rencontrent en Roumanie et la question du projet de conférence balkanique est à nouveau évoquée ${ }^{22}$. L'implication directe des Roumains dans le lancement du plan est arrêtée lors du voyage à Moscou du vice-président du Conseil, Emil Bodnăraş, et du ministre des Affaires étrangères, Ion Gheorghe Maurer, à la mi-août ${ }^{23}$. Ce dernier se rend à Belgrade quinze jours plus tard, pour des discussions qui prennent l'allure d'une acceptation programmée du futur plan Stoica par la Yougoslavie ${ }^{24}$, cependant que des sondages ont lieu à Tirana au même moment. Les sources roumaines nous permettent de suivre ces derniers avec précision: lors de leur visite officielle dans la capitale albanaise, Gheorghe Apostol et Grigore Preoteasa, les représentants du Parti ouvrier roumain (Partidul muncitoresc român - PMR) font ainsi très explicitement référence à un document établi lors des entretiens préalables de Moscou, concernant le projet de conférence balkanique ${ }^{25}$. Mais pourquoi les Soviétiques ont-ils désigné la Roumanie pour porter ce projet ? Et dans quelle mesure la Grèce en est-elle la principale cible?

\section{Pourquoi la Roumanie ? Et pourquoi la Grèce?}

9 Pour répondre à ces questions, le plan Stoica doit être compris comme maillon d'une stratégie plus large, conditionnée par l'évolution de la situation en Europe et notamment en Allemagne et à Chypre, ainsi que par les soubresauts des relations gréco-américaines. La récente victoire électorale de la Christlich Demokratische Union (CDU) en Allemagne compromet en effet les projets soviétiques de zone dénucléarisée en Europe centrale - il s'agit du premier plan Rapacki, un ensemble de propositions présentées par Adam Rapacki, ministre polonais des Affaires étrangères, devant l'Assemblée générale des Nations Unies, le 2 octobre 195726. Moscou développe par conséquent, pour reprendre les termes employés par la diplomatie française, «son "offensive de paix" latéralement: en Europe du Nord, avec la campagne pour la neutralisation de la Baltique et [...] au sud, dans les Balkans ${ }^{27}$ ». Seul, ce volontarisme n'est cependant pas suffisant pour comprendre les objectifs poursuivis à travers le plan Stoica. Il faut pour cela se pencher plus avant sur la situation des liens de la Grèce avec ses partenaires de l'Organisation du traité de l'Atlantique Nord (OTAN). 
10 En 1956-1957, les relations entre la Grèce et les États-Unis ne sont pas au beau fixe : le gouvernement américain refuse d'accorder à Athènes les aides économiques et militaires qu'elle sollicite ${ }^{28}$, ainsi que de la soutenir contre la Turquie dans son projet de récupérer Chypre. D'un point de vue militaire, il est pourtant très sérieusement question de renforcer la contribution grecque au dispositif des forces de l'OTAN en Europe, à travers l'installation de batteries de missiles balistiques intercontinentaux Jupiter et Thor $^{29}$ - ce qui aurait pour effet non négligeable de mettre l'Union soviétique à portée du feu américain. En tentant d'associer la Grèce au plan Stoica, il s'agit par conséquent, d'abord et avant tout, d'écarter cette perspective, à travers la sanctuarisation du sol grec. Les dirigeants soviétiques ont d'ailleurs précédemment exploré eux-mêmes la voie d'un réchauffement immédiat des relations entre Athènes et Moscou, en tentant de se rapprocher de leurs homologues grecs. En visite dans la capitale grecque au mois de juin 1956, le ministre des Affaires étrangères de l'URSS, Dmitri Chepilov, s'est ainsi dit «prêt à donner à la Grèce des garanties contre une agression $^{30}$ » bulgare ou albanaise. Or le plan Stoica va justement dans ce sens, et c'est ce que souligne à la tribune de l'ONU le nouveau chef de la diplomatie soviétique, Andreï Gromyko, lors de la session de l'Assemblée générale qui vient de lancer ses travaux en septembre $1957^{31}$.

11 Au-delà des discours sur la garantie des frontières, au-delà du volet portant sur la coopération économique et culturelle, le principal enjeu de ce plan Stoica est bien la question des missiles ${ }^{32}$. La «zone de paix » initialement proposée devient ainsi une "zone dénucléarisée ». Le glissement sémantique n'est pas anodin et montre bien que toute l'opération est " évidemment dirigée contre le système défensif atlantique dans l'Europe du Sud-Est ${ }^{33}$ ». Or cette orientation répond davantage aux intérêts stratégiques de l'URSS qu'à ceux de la Roumanie. À Washington, le sous-secrétaire d'État aux questions européennes, Charles Burke Elbrick, n'est pas dupe : "Cette manœuvre encouragée par Moscou [a] pour but principal, de semer le doute dans les esprits en Grèce [et en Turquie] et de les détourner si possible de l'Alliance atlantique ${ }^{34}$ ", affirme-t-il à l'ambassadeur de France à Washington. Par ailleurs, si la Grèce est bien la principale cible du projet, la Yougoslavie est également en ligne de mire; le maréchal Tito est en effet contraint de clarifier ses positions à l'égard des pays voisins, ainsi que de réactualiser la prééminence de son alliance avec les pays socialistes, par rapport au traité d'Ankara ${ }^{35}$ qui le lie aux puissances balkaniques engagées dans l'OTAN ${ }^{36}$. Le plan Stoica s'apparente donc de ce point de vue à une stratégie du cheval de Troie.

Mais pourquoi Moscou a-t-elle choisi de faire de la Roumanie le porte-drapeau de ce projet dont elle est la véritable inspiratrice? Pourquoi accorder aux dirigeants roumains, Gheorghe Gheorghiu-Dej et son équipe, cette satisfaction de prestige - une « satisfaction de vanité ${ }^{37}$ » dira le représentant français à Bucarest - à travers ce projet régional dont les retombées en matière d'image vont bien au-delà des frontières du camp socialiste? Il s'agit, dans une certaine mesure, de récompenser la fidélité à toute épreuve témoignée par la Roumanie à l'URSS dans le contexte de la crise hongroise, que nous soulignions précédemment. Cela lui offrirait ainsi la possibilité d'acquérir une aura sur la scène diplomatique internationale, mais aussi au sein du bloc communiste ${ }^{38}$. Néanmoins, derrière le paravent des "civilités socialistes ", il faut sans doute déceler une part de realpolitik. Par sa situation géographique au cœur des Balkans, la Roumanie est la mieux placée parmi les satellites pour prendre cette initiative; au vu des bons rapports qu'elle entretient avec la Yougoslavie et l'Albanie, mais aussi avec la Grèce et 
la Turquie, elle est la mieux placée pour réussir dans cette entreprise de déstabilisation périphérique du bloc de l'Ouest. Ses relations avec la Grèce sont d'ailleurs sur une pente ascendante - rappelons la signature, en août 1955, d'un accord économique roumano-grec et d'une déclaration sur la reprise des relations diplomatiques effective en 1956. Pourtant, nous allons voir que l'échec du plan Stoica est inéluctable. Demeure par conséquent la question des résultats objectivement escomptés.

\section{Échec programmé, avantage propagandiste} est en effet inenvisageable pour un tel projet : l'on sait pertinemment, à Moscou comme à Bucarest, qu'en raison de leur désaccord au sujet de la question chypriote, il sera impossible de toucher à la fois la Grèce et la Turquie ; l'on sait aussi que la diplomatie américaine ne laissera pas sortir de son orbite ces deux alliés stratégiques. Mais si l'initiative roumaine ne fait pas vaciller la solidité de l'OTAN, elle suscite néanmoins des effets d'annonce non négligeables, car Athènes ne la rejette pas d'emblée et déclare dans un premier temps la prendre en considération. In fine, le refus grec est encore intéressant, car il intervient au terme d'un processus exploitable en matière de propagande. Le ministre grec des Affaires étrangères affirme en effet, maladroitement, que son pays a fait « examiner l'invitation roumaine ${ }^{39}$ " par l'OTAN. Si une concertation entre partenaires n'a rien de surprenant, le syntagme "examiner par» révèle l'existence d'un «droit de regard» des puissances occidentales, non seulement sur la position internationale de la Grèce, mais également dans son environnement régional. L'ambassadeur de France à Athènes affirme d'ailleurs être en contact permanent avec son homologue américain, afin d'œuvrer à la définition d'une ligne de conduite commune - celle du refus du plan Stoica - entre Athènes et Ankara ${ }^{40}$.

Côté soviétique, l'intérêt réside par conséquent dans la capitalisation de cet échec à des fins de propagande, dans un contexte délicat, puisque la session de l'Assemblée générale de l'ONU qui vient de s'ouvrir en septembre 1957 s'apprête à condamner l'URSS pour son intervention militaire en Hongrie un an plus tôt. Le message qu'il s'agit de dégager à travers le plan Stoica - et son inévitable échec - est manichéen : les « démocraties populaires » sont porteuses de paix ; les impérialistes et les pays asservis par l'OTAN sont des fauteurs de guerre. De ce point de vue, l'initiative portée par le gouvernement roumain constitue pour le camp socialiste une véritable «bonne affaire ", exploitable quelle qu'en soit l'issue. En cas d'acceptation du projet, même par seulement certains des protagonistes, c'est l'URSS, au-delà de la Roumanie, qui en retire une gloire en tant que promoteur des initiatives de paix. En cas de refus, c'est une formidable occasion pour la propagande soviétique de mettre en accusation la non-réceptivité de l'Occident et de ses alliés aux ouvertures pacifiques du camp socialiste.

eration de septembre 1957 est donc un " échec réussi », à tel point que l'on assiste dès lors régulièrement à des relances similaires de projets régionaux de dénucléarisation. Le plan Rapacki pour l'Europe centrale doit associer la République fédérale d'Allemagne (RFA), la République démocratique allemande (RDA), la Tchécoslovaquie et la Pologne. Il a pour but de limiter la capacité de défense située en Allemagne de l'Ouest et de "créer ainsi en Europe une situation permanente de déséquilibre en faveur des puissances groupées à l'Est autour de l'URSS, laquelle n'a pas 
renoncé à ses moyens nucléaires ${ }^{41} »$. La proposition polonaise connaît des remaniements successifs et notamment une relance en janvier $1958^{42}$, jusqu'à aboutir à sa forme finale, soumise sous forme de mémorandum par la délégation polonaise lors de la Conférence du Comité des dix-huit puissances sur le désarmement réuni à Genève, le 28 mars 1962. Le plan Rapacki, qui devient le plan Gomułka ${ }^{43}$ en décembre 1962, dépasse donc les ambitions de paix et de coopération du plan Stoica. Le plan Stoica est lui aussi une première fois relancé en 1959. Le camp soviétique observe alors, impuissant, le rapprochement entre la Grèce et la Turquie, facilité par le règlement de la question de Chypre ; les relations entre la Yougoslavie et la Grèce sont également au beau fixe, comme le prouvent les récents entretiens Tito-Caramanlis à Rhodes ${ }^{44}$. Ces évolutions font craindre la reconstitution d'un axe Athènes-Belgrade-Ankara. C'est pourquoi, le 30 mai 1959, Nikita Khrouchtchev fait siennes les propositions du plan Stoica, en présentant à Tirana un projet concernant non seulement les Balkans, mais aussi l'Adriatique et comprenant l'Italie ${ }^{45}$. À travers ces relances, il s'agit de contrer la consolidation du système d'alliances occidental dans la région. La Roumanie revient à son tour à la charge en 1962, proposant un plan de neutralisation des Balkans, baptisé cette fois plan Gheorghiu-Dej. Le 28 mars 1962, le ministre des Affaires étrangères de la RPR, Corneliu Mănescu, soumet au Comité des dix-huit puissances pour le désarmement, à Genève, une proposition roumaine de neutralisation des Balkans ${ }^{46}$. Devant la Grande Assemblée nationale réunie en session plénière, le Premier secrétaire du PMR s'exprime à son tour le 24 juin 1962. Ce discours est l'occasion pour le leader roumain de rappeler les principes présidant à la conception de la diplomatie roumaine - parmi lesquels la sauvegarde d'un climat de détente au niveau international figure en bonne place -, ainsi que de reformuler la proposition de création d'une zone dénucléarisée dans les Balkans :

Le gouvernement de la RPR lance à nouveau un appel à l'union des forces de tous les pays balkaniques, en vue de la conclusion d'un traité d'entente et de sécurité collective dans les Balkans; il transformerait les Balkans en zone de paix dépourvue d'armes nucléaires et de fusées, en zone d'amitié et de collaboration, de travail pacifique et de prospérité pour le plus grand bien de tous les peuples de cette partie du monde ${ }^{47}$.

16 De nouveau, la proposition roumaine reste dépourvue d'effet; de nouveau, cela était hautement prévisible. Le ton du discours est agressif, Gheorghiu-Dej pointe du doigt la Grèce et la Turquie comme les principales responsables de l'échec du plan Stoica. Il ironise même sur le bien-fondé et l'avantage réciproque de l'Alliance occidentale contractée par ces deux pays: "Lors de la récente session de l'OTAN, les leaders occidentaux ont adressé des "félicitations" à la Grèce et à la Turquie pour le fait que bien que leur niveau de vie soit l'un des plus bas parmi les pays de l'OTAN, ces deux pays se placent en tête des États membres de l'OTAN par rapport aux dépenses militaires ${ }^{48}$ ", se gausse le Premier secrétaire du PMR.

17 L'absence d'écho rencontrée par leurs propositions n'empêche nullement les dirigeants roumains de poursuivre leur activisme propagandiste en faveur de la zone de paix dans les Balkans, comme en témoigne la tenue à Bucarest d'une session de la Conférence pour la compréhension et la collaboration entre pays balkaniques, du 27 au 29 mai $1963^{49}$. En septembre 1963 est débattue lors de l'Assemblée générale des Nations Unies une proposition visant à faire de l'Amérique latine une zone désatomisée. À cette occasion, la Roumanie se prononce en faveur du projet ${ }^{50}, \mathrm{y}$ voyant un exemple d'action de paix au plan régional semblable en tous points à celle dont elle a été 
officiellement l'instigatrice avec le plan Stoica. Elle exploite par conséquent la proposition brésilienne afin de remettre la question de la transformation des Balkans en zone de paix sur le devant de la scène, son ministre des Affaires étrangères, Corneliu Mănescu, évoquant même la question dans un entretien avec le secrétaire d'État, Dean Rusk, le 21 octobre $1963^{51}$. Les mêmes causes produisant les mêmes effets, l'initiative échoue. Lors d'une visite faite à Ankara en mars 1969, Nicolae Ceauşescu relance à son tour l'idée de désatomisation des Balkans ${ }^{52}$.

\section{Conclusion}

En conclusion, leur statut d'alliés irréprochables lors de la crise hongroise de 1956 vaut aux dirigeants roumains la reconnaissance de l'équipe khrouchtchévienne. Avec le plan Stoica d'entente balkanique de septembre 1957, les Soviétiques les autorisent à porter un projet potentiellement d'envergure. Mais ce plan sert les intérêts soviétiques et c'est à Moscou que sont définies les orientations des relations roumano-grecques, qui continuent d'être régies par la logique des blocs et une sorte de division socialiste des tâches - à la Roumanie, les Balkans, à la Pologne, l'Europe centrale. Le plan Stoica est un échec, car du côté grec les atouts de l'Alliance atlantique l'emportent sur les ouvertures faites par le bloc de l'Est. La logique mondiale de guerre froide l'emporte sur la logique régionale de coopération balkanique. Ce type d'action a néanmoins un avantage: il permet aux dirigeants roumains de s'exercer au maniement de la rhétorique de l'égalité en droits, de la souveraineté nationale, de la non-immixtion dans les affaires internes et des relations avec des pays à régimes politiques et sociaux différents. Certes, ces catégories peuvent dans un premier temps sembler creuses et éculées; mais Gheorghiu-Dej et son équipe s'approprient progressivement ces concepts, les prennent au pied de la lettre et en font dans les années 1960 des armes au service de la désatellisation. En revanche, il est intéressant de constater que lorsque la Roumanie s'affranchit progressivement de la tutelle soviétique, c'est vers l'Europe occidentale qu'elle choisit de se tourner, et non vers la Grèce. La France et la RFA ont sa préférence pour des raisons stratégiques, liées aux transferts de technologies et aux achats de biens d'équipements. Un parallèle peut être fait avec l'orientation de plus en plus européenne de la diplomatie grecque, qui se solde par la négociation d'un accord de coopération avec la Communauté économique européenne (CEE) dès 1959. Enfin, le dernier élément notable réside dans l'importance de la question chypriote: dès 1957, celle-ci alimente une sorte de chantage des autorités grecques concernant leur participation à l'Alliance atlantique ; dans les années 1970, l'on retrouve cette même question comme déterminant de la politique extérieure grecque et d'un éventuel rapprochement avec le bloc de l'Est ${ }^{53}$. 


\section{BIBLIOGRAPHIE}

BÉKÉS Csaba, BYRNE Malcolm, RAINER János (eds.), 2002, The 1956 Hungarian Revolution: A History in Documents, Budapest-New York: Central European University Press.

BLOUDANIS Nicolas, 2013, Histoire de la Grèce moderne 1828-2012. Mythes et réalités, Paris : L'Harmattan. BOCA Ioana, 2001, 1956: Un an de ruptură. România între internaţionalismul proletar şi stalinismul antisovietic, Bucureşti: FundaŢia Academia civică.

CIUCEANU Radu et al. (eds.), 1997, Misiunile lui A.I. Vâş̧inski în România. Din istoria relaţiilor româno-sovietice, 1944-1946. Documente secrete, Bucureşti: INST.

DOBRINCU Dorin, 2003, “The Soviet Counsellors' Involvement in Postwar Romanian Repressive and Military Structures", in Alexandru zUB et al. (dir.), Sovietization in Romania and Czechoslovakia. History, Analogies, Consequences, Iaşi: Polirom, pp. 157-174.

GRIDAN Irina, 2013, le Satellite récalcitrant. La Roumanie de Gheorghiu-Dej face à l'URSS : acteurs, vecteurs et enjeux d'une politique extérieure sous influence (1944-1965), thèse de doctorat, Université Paris I - Panthéon-Sorbonne.

HATZIVASSILIOU Evanthis, 2006, Greece and the Cold War: Frontline state, 1952-1967, London: Routledge. LIPATTI Valentin, POTRA George G., TURCU Constantin I. (éd.), 1981, Titulescu : notre contemporain, Paris : Nagel.

PĂIUŞAN Cristina, 2000, „Timişoara 1956. O încercare de revoltă anticomunistă”, Arhivele totalitarismului, nr. 1-2, p. 87-104.

PELT Mogens, 2006, Tying Greece to the West: US - West Germany - Greek Relations, 1949-1974, Copenhagen: Museum Tusculanum Press.

REY Marie-Pierre, 1997, l'URSS et l'Europe occidentale de 1953 à 1975, contribution à une histoire de la politique extérieure soviétique, mémoire pour l'habilitation à diriger des recherches, Université Paris I - Panthéon-Sorbonne.

SCURTU Ioan (ed.), 1996, România. Retragerea trupelor sovietice, 1958, Bucureşti: Editura didactică şi pedagogică.

SCURTU Ioan, 1998, „Consilierii sovietici în România”, Magazin istoric, nr. 5, p. 12-15.

SITARIU Mihaela (ed.), 2004, Oaza de libertate: Timişoara, 30 octombrie 1956, Iaşi: Polirom.

STYKALIN Aleksandr, 2005, „RelaŢiile soviéto-iugoslave şi afacerea Imre Nagy”, Arhivele totalitarismului, nr. 3-4, p. 50-76.

\section{NOTES}

1. Irina Gridan a soutenu en 2013 à l'université Paris I - Panthéon-Sorbonne une thèse intitulée le Satellite récalcitrant. La Roumanie de Gheorghiu-Dej face à l'URSS: acteurs, vecteurs et enjeux d'une politique extérieure sous influence (1944-1965).

2. Pour le retrait des conseillers, voir Ioan SCURTU (ed.), 1996, România. Retragerea trupelor sovietice, 1958, Bucureşti: Editura didactică şi pedagogică. 
3. Les conseillers soviétiques ont fait leur apparition lors des visites en Roumanie d'Andreï Vychinski, entre 1944 et 1946. Voir Radu ciucEAnu et al. (eds.), 1997, Misiunile lui A.I. Vâş̧inski în România. Din istoria relaţiilor româno-sovietice, 1944-1946. Documente secrete, Bucureşti: INST.

4. Le rôle de l'influence des conseillers et des spécialistes est primordial dans tous les domaines de la vie politique, économique et sociale. Voir Ioan SCURTU, 1998, „Consilierii sovietici în România", Magazin istoric, nr. 5, p. 12-15 ; Dorin DoBRINCU, 2003, "The Soviet Counsellors' Involvement in PostWar Romanian Repressive and Military Structures", in Alexandru zUB et al. (dir.), Sovietization in Romania and Czechoslovakia. History, Analogies, Consequences, Iaşi: Polirom, pp. 157-174.

5. „DeclaraŢia guvernului sovietic din 30 octombrie 1956”, Scânteia, 31 octobre 1956.

6. Archives du ministère français des Affaires étrangères (AMFAE), Europe 1956-1960, URSS, 287, télégramme à l'arrivée $n^{\circ} 4277,31$ octobre 1956, Moscou, Dejean.

7. AMFAE, Europe 1956-1960, Roumanie, 143, dépêche $n^{\circ}$ 839/EU, 20 septembre 1957, Athènes, Pierre Charpentier à Christian Pineau. À noter que la lettre transmise aux autorités bulgares est quasiment identique à celle envoyée à Athènes. AMFAE, Europe 1956-1960, Roumanie, 143, dépêche $n^{\circ} 565 / \mathrm{EU}, 21$ septembre 1957, Sofia, Beausse à Pineau.

8. AMFAE, Europe 1956-1960, Roumanie, 143, dépêche n 839/EU, 20 septembre 1957, Athènes, Pierre Charpentier à Christian Pineau, lettre de Stoica à Caramanlis.

9. Valentin LIPATTI, George G. POTRA et Constantin I. TURCU (éd.), 1981, Titulescu : notre contemporain, Paris : Nagel.

10. AMFAE, Europe 1956-1960, Roumanie, 143, dépêche n 565/EU, 21 septembre 1957, Sofia, Beausse à Pineau.

11. AMFAE, Europe 1956-1960, Roumanie, 143, télégramme à l'arrivée $\mathrm{n}^{\circ}$ 1049-1052, 22 septembre 1957, Ankara, Spitzmüller.

12. AMFAE, Europe 1956-1960, Roumanie, 143, dépêche n 857/EU, 26 septembre 1957, Athènes, Charpentier.

13. AMFAE, Europe 1956-1960, Roumanie, 143, dépêche $n^{\circ}$ 684/EU, 13 août 1957, Deciry à Pineau.

14. Le Bureau politique se réunit régulièrement afin de condamner ce qui se passe en Hongrie et de prendre des mesures de cordon sanitaire. Voir Archives nationales historiques centrales (ANIC), Comité central du Parti communiste roumain (CC al PCR), Cancelarie II, 169/1956, procès-verbal de la réunion du Bureau politique, 24 octobre 1956, p. $3 ; 170 / 1956$, procès-verbal de la réunion du Bureau politique du 26 octobre 1956, p.1-5. Pour une approche combinant analyse et éclairages documentaires sur la position roumaine dans le contexte de l'année 1956, voir Ioana BOCA, 2001, 1956: Un an de ruptură. România între internaţionalismul proletar şi stalinismul antisovietic, Bucureşti: FundaŢia Academia civică. Sur les échos roumains aux événements hongrois, voir Mihaela SITARIU (ed.), 2004, Oaza de libertate: Timişoara, 30 octombrie 1956, Iaşi: Polirom ; Cristina PĂIUşAN, 2000, „Timişoara 1956. O încercare de revoltă anticomunistă", Arhivele totalitarismului, nr. 1-2, p. 87-104.

15. «Le peuple hongrois anéantit le complot contre-révolutionnaire", Informaţia, 4 novembre 1956. 
16. Rapport de Malenkov, Souslov et Aristov du 17 novembre, in Csaba BÉKÉs, Malcolm BYRNE and János RAINER (eds.), 2002, The 1956 Hungarian Revolution: A History in Documents, Budapest-New York: Central European University Press, pp.435-436; Aleksandr STYKALIN, 2005, „RelaŢiile soviéto-iugoslave şi afacerea Imre Nagy”, Arhivele totalitarismului, nr. 3-4, p. 50-76.

17. AMFAE, Europe 1956-1960, Roumanie, 143, dépêche nº 684/EU, 13 août 1956, Deciry à Pineau.

18. Pravda du 7 août 1956.

19. AMFAE, Europe 1956-1960, Roumanie, 143, télégramme à l'arrivée $\mathrm{n}^{\circ} 3830$, 23 septembre 1957, Moscou, Soutou : «Le gouvernement soviétique affecte de se tenir à l'écart de toute cette affaire et de la considérer comme du ressort des seuls États balkaniques. »

20. AMFAE, Europe 1956-1960, Roumanie, 143, télégramme à l'arrivée $\mathrm{n}^{\circ}$ 3839-3840, 24 septembre 1957, Moscou, Soutou.

21. Déclaration faite en 1995 dans une interview du Centre d'histoire orale de la radiodiffusion roumaine, in Steliu LAMBRU, „România şi Balcanii după 1945”, consulté le 8 juin 2014 sur le site : http://old.rri.ro/arh-art.shtml?lang=2\&sec=40\&art=60502.

22. Ce fait est corroboré par l'évocation de la rencontre dans ANIC, CC al PCR, Cancelarie II, 85/1957, lettre de Khrouchtchev à Gheorghiu-Dej, 24 octobre 1957, p. 1.

23. Pour les pourparlers du 17 août, voir ANIC, CC al PCR, SecŢia relaŢii externe III, 55/1957 ; AMFAE, Europe 1956-1960, Roumanie, 143, télégramme à l'arrivée nº 345-347, 22 septembre 1957, Bucarest, Deciry.

24. AMFAE, Europe 1956-1960, Roumanie, 143, télégramme à l'arrivée $\mathrm{n}^{\circ}$ 1051-1061, 20 septembre 1957, Belgrade, Broustra.

25. ANIC, CC al PCR, Seç̧ia relaţii externe III, 40/1957, compte-rendu des pourparlers roumano-albanais de Tirana du 29 août 1957 ; ANIC, CC al PCR, Seç̧ia relaŢii externe III, 74/1957, minutes d'un entretien avec Mehmet Shehu.

26. Sur les implications du plan Rapacki, voir Marie-Pierre REY, 1997, l'URSS et l'Europe occidentale de 1953 à 1975, contribution à une histoire de la politique extérieure soviétique, mémoire pour l'habilitation à diriger des recherches, Université Paris IPanthéon-Sorbonne, p. 237-239.

27. AMFAE, Europe 1956-1960, Roumanie, 143, télégramme au départ $\mathrm{n}^{\circ}$ 928-930, 18 septembre 1957, Laloy.

28. Mogens PELT, 2006, Tying Greece to the West: US - West Germany-Greek Relations, 1949-1974, Copenhagen: Museum Tusculanum Press, p. 154.

29. Ibid., p. 176.

30. AMFAE, Europe 1956-1960, Roumanie, 143, télégramme à l'arrivée $\mathrm{n}^{\circ} 627$, 19 septembre 1957, Athènes, Charpentier.

31. AMFAE, Europe 1956-1960, Roumanie, 143, télégramme à l'arrivée $\mathrm{n}^{\circ}$ 345-347, 22 septembre 1957, Bucarest, Deciry.

32. Todor Jivkov ne s'y trompe pas, qui en répondant aux Roumains souligne qu'il s'agit avant tout de transformer les Balkans « en zone dépourvue d'armes atomiques et de rampes de lancement ». AMFAE, Europe 1961-1970, Roumanie, 211, note du 9 juin 1964. 
33. AMFAE, Europe 1956-1960, Roumanie, 143, télégramme au départ $\mathrm{n}^{\circ}$ 928-930, 18 septembre 1957, Laloy.

34. AMFAE, Europe 1956-1960, Roumanie, 143, télégramme à l'arrivée n 5805-5809, 23 septembre 1957, Washington, Alphand.

35. Il s'agit du traité signé à Ankara le 28 février 1953 par la Yougoslavie, la Grèce et la Turquie. Implicitement destiné à limiter l'influence soviétique dans les Balkans, il constitue une manière indirecte pour la Yougoslavie de coopérer avec l'OTAN, dont la Grèce et la Turquie sont membres. La réconciliation soviéto-yougoslave en limite la portée.

36. AMFAE, Europe 1956-1960, Roumanie, 143, télégramme à l'arrivée nº 1051-1061, 20 septembre 1957, Belgrade, Broustra.

37. AMFAE, Europe 1956-1960, Roumanie, 143, dépêche $\mathrm{n}^{\circ}$ 715/EU, 9 octobre 1957, Bucarest, Deciry à Pineau.

38. AMFAE, Europe 1956-1960, Roumanie, 143, dépêche $n^{\circ}$ 691/EU, 25 septembre 1957, Bucarest, Deciry: «Si le gouvernement roumain en a retiré quelque satisfaction de vanité, le rôle que Moscou lui a fait jouer consolide beaucoup son prestige. »

39. AMFAE, Europe 1956-1960, Roumanie, 143, télégramme à l'arrivée $\mathrm{n}^{\circ} 625$, 18 septembre 1957, Athènes, Charpentier.

40. AMFAE, Europe 1956-1960, Roumanie, 143, télégramme à l'arrivée $n^{\circ} 626$, 18 septembre 1957, Athènes, Charpentier.

41. AMFAE, Europe 1961-1970, Roumanie, 211, note du 9 juin 1964.

42. Pour le texte de la proposition du 14 février 1958, voir http://www.cvce.eu/ viewer/-/content/c7c21f77-83c4-4ffc-8cca-30255b300cb2/fr, consulté le 17 novembre 2012.

43. Le plan Gomułka ne retient en fait que la première étape du plan Rapacki, à savoir la recherche du «statu quo atomique ».

44. Sur ces entretiens de mars 1959, voir Evanthis HATZIVASSILIOU, 2006, Greece and the Cold War: Frontline state, 1952-1967, London: Routledge, pp. 111-112.

45. Sur les premières «offres de dénucléarisation» soviétiques en Europe, voir Marie-Pierre REY, l'URSS et l'Europe occidentale de 1953 à 1975..., op. cit., p. 233-237.

46. AMFAE, Europe 1961-1970, Roumanie, 211, note du 9 juin 1964.

47. AMFAE, Europe 1961-1970, Roumanie, 211, télégramme à l'arrivée $n^{\circ} 572$, 25 juin 1962, Bucarest, Boiberranger.

48. AMFAE, Europe 1961-1970, Roumanie, 211, télégramme à l'arrivée $n^{\circ} 572$, 25 juin 1962, Bucarest, Boiberranger.

49. L'Albanie est absente de cette $3^{\mathrm{e}}$ session, mais l'Italie et Chypre y sont représentées.

50. Elle est la seule parmi les pays socialistes à voter favorablement, les autres s'abstenant.

51. ANIC, CC al PCR, Secţia relaŢii externe IV, 91/1963, compte-rendu des entretiens Mănescu-Rusk rédigé par les services du MAE, 30 octobre 1963, p. 36-49.

52. AMFAE, Europe 1961-1970, Roumanie, 213, télégramme à l'arrivée $n^{\circ} 235-241$, 26 mars 1969, Bucarest : "La transformation des Balkans en une zone de paix et de bon voisinage dépourvue de l'arme atomique, serait une contribution de la plus grande 
importance pour la consolidation de la paix et le renforcement de la sécurité dans le monde entier.»

53. Nicolas BLOUDANIS, 2013, Histoire de la Grèce moderne 1828-2012. Mythes et réalités, Paris : L'Harmattan, p. 192: «Après 1974, l'ambiguïté de la politique extérieure grecque devient officielle: sortie puis rentrée [dans] l'OTAN, déclarations ambivalentes de ministres sur de possibles facilités accordées à la flotte russe dans des îles grecques, tièdement démenties quelques jours plus tard par Caramanlis, achats de matériel militaire (de transport) à la Roumanie et à la Pologne, expriment une volonté de faire sentir aux Occidentaux que les alliances ne sont pas immuables, également en utilisant les soubresauts nationalistes de l'opinion.»

\section{RÉSUMÉS}

La guerre froide enregistre un tournant avec l'adoption de la doctrine de la coexistence pacifique par l'URSS. Pour autant, ce virage idéologique a-t-il des répercussions sur les relations entre la Roumanie et la Grèce, chacune dans l'ombre respectivement de l'URSS et des États-Unis? L'objectif de cet article est d'interroger les spécificités et les similarités des rôles de ces deux pays dans des dispositifs géopolitiques qui les transcendent, tout en s'interrogeant sur le caractère mouvant des frontières de guerre froide : les blocs peuvent-ils avoir une géographie variable ? À partir du plan Stoica de dénucléarisation des Balkans proposé par Bucarest à Athènes en septembre 1957, l'étude analyse les objectifs du rapprochement roumano-grec, ses limites, ainsi que ses retombées en matière de propagande. Ce faisant, elle montre que du côté roumain - et soviétique - le plan Stoica œuvre à une déstabilisation périphérique du bloc de l'Ouest ; du côté grec, il permet d'exercer une sorte de chantage à la participation à l'Alliance atlantique même si, in fine, la logique mondiale de guerre froide l'emporte sur la logique régionale de coopération balkanique.

The Cold War experienced a turning point with the adoption by the USSR of the doctrine of the peaceful coexistence. However, had this ideological shift had consequences on the relationship between Romania and Greece, each one being in the respective shadow of the USSR and of the United States? The aim of this article is to consider the specificities and the similarities of the roles of these two countries in geopolitical structures that transcend them. Hence, it questions the stability of the cold war borders: may the blocs have a variable geography? From the Stoica plan of balkanic denuclearization that Bucharest proposed to Athens in September 1957, the study analyses the goals of the Romanian-Greek rapprochement, its limits and its benefits in terms of propaganda. In doing so, it shows that for the Romanian and the Sovietic sides, the Stoica plan allows a peripheral destabilization of the Western camp; for the Greek side, it allows a kind of blackmail around the participation to the Atlantic alliance. Nevertheless, the global logic of Cold War finally triumphs over the regional logic of Balkan cooperation.

Războiul rece cunoaște un moment de cotitură atunci când URSS adoptă doctrina coexistenȚei pașnice. $\mathrm{Cu}$ toate acestea, a avut oare acest viraj ideologic repercusiuni asupra relaȚiilor dintre România și Grecia, aflate respectiv în umbra Uniunii sovietice și cea a Statelor Unite? Scopul acestui articol este de a examina specificităȚile și similarităȚile rolurilor acestor două Țări în 
dispozitive geopolitice care le depășesc, și totodată de a chestiona caracterul instabil al frontierelor de război rece: pot oare blocurile avea o geografie variabilă? Plecând de la planul Stoica de denuclearizare a Balcanilor propus de București Atenei în septembrie 1957, studiul analizează obiectivele apropierii româno-grecești, limitele sale, precum și impactul său propagandistic. Se arată că din punctul de vedere român - și sovietic - planul Stoica lucrează la o destabilizare periferică a blocului occidental; din punctul de vedere grec, permite un fel de șantaj a cărui miză este participarea la alianța atlantică, deși, într-un sfârșit, logica mondială de război rece se impune faȚă de cea regională de cooperare balcanică.

\section{INDEX}

motsclestr Balkan Antantı, Yunan-Romen ilişkileri, Soğuk Savaş, Barış içinde bir arada yaşama, Romanya, Yunanistan, Türkiye, Balkanlar, yirminci yüzyıl, Diplomatik Tarih

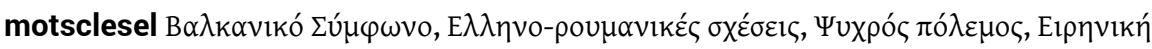

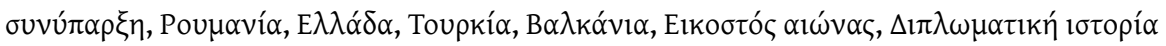

Index géographique : Roumanie, Grèce, Turquie

motsclesmk БАЛКАНСКИ ПАКТ, ГРЦИЈА /РОМАНИЈА ОДНОСИ, СТУДЕНА ВОЈНА, МИРЕН СОЖИВОТ, РОМАНИЈА, ГРЦИЈА, ТУРЦИЈА, БАЛКАНОТ, ДВАЕСЕТТИОТ ВЕК, ДИПЛОМАТСКА ИСТОРИЈА

Thèmes : Histoire diplomatique

Mots-clés : Entente balkanique, Entente balkanique, relations gréco-roumaines, relations grécoroumaines, guerre froide, guerre froide, coexistence pacifique, coexistence pacifique, Stoica Chivu (1908-1975)

Keywords : Balkan Pact, Greek-Romanian relations, Cold War, Peaceful coexistence, Romania, Greece, Turkey, Balkan, Twentieth century, Diplomatic History

Index chronologique : vingtième siècle

\section{AUTEUR}

\section{IRINA GRIDAN}

Professeur agrégée d'histoire, chercheur à l'UMR IRICE 